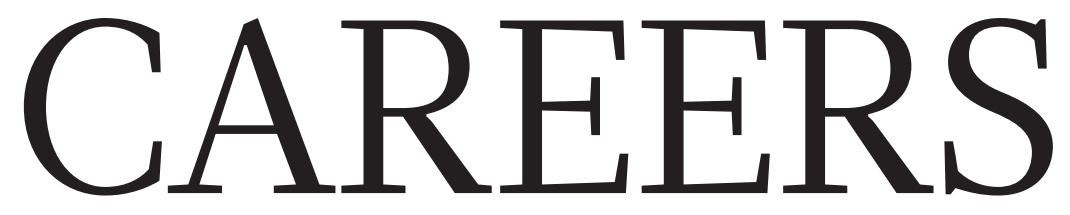

TURNING POINT Chemist's move into energy research earns him a growing lab p.243
EUROPEAN UNION PhD scheme will combine science with business innovation $\mathbf{p . 2 4 3}$
NATUREJOBS For the latest career listings and advice www.naturejobs.com

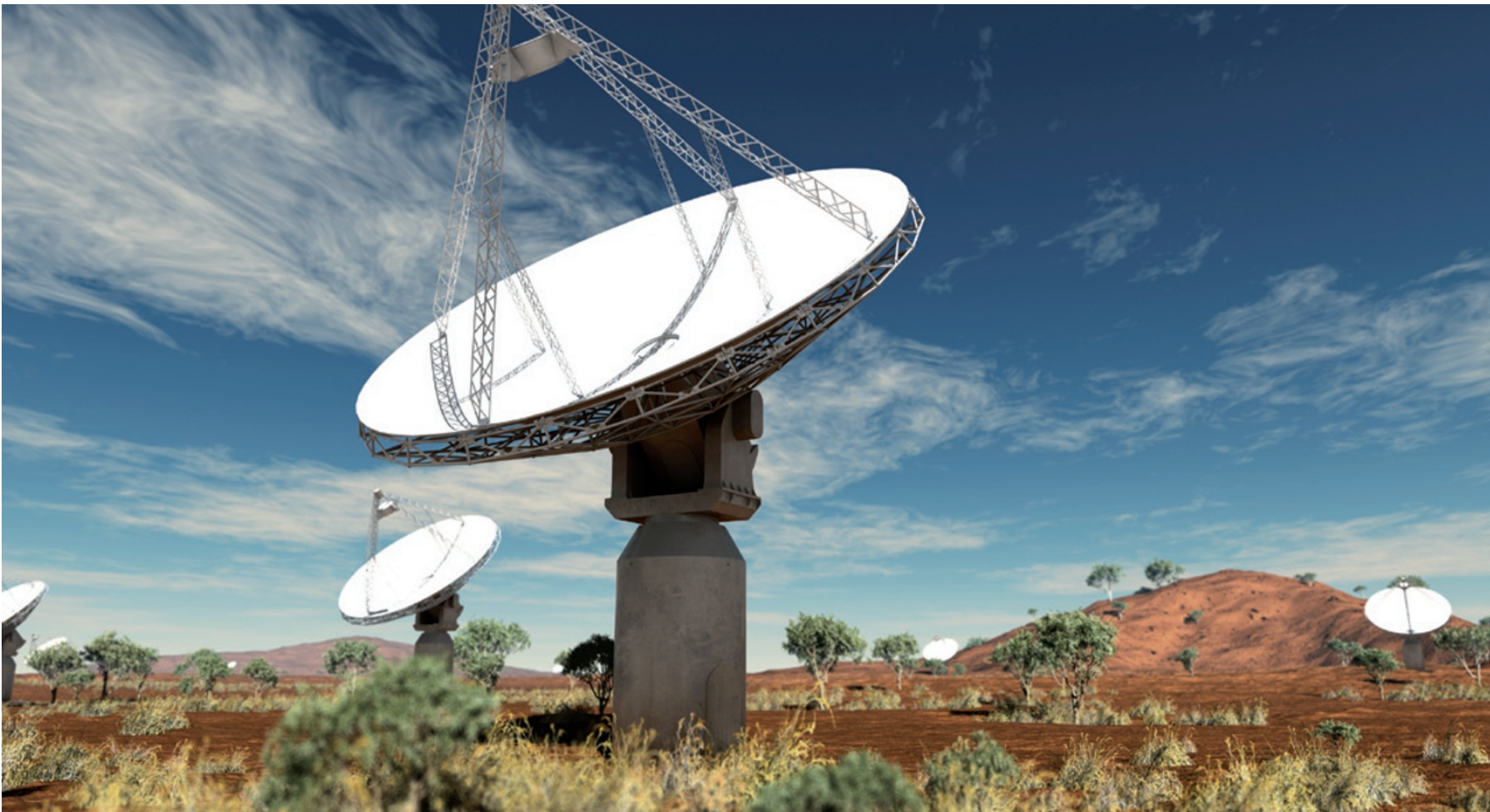

Artist's impression of the Australian Square Kilometre Array Pathfinder radio telescope to be built at the Murchison Radio-astronomy Observatory.

\title{
Astronomy in the outback
}

\section{A bid to host a major international radio telescope has created a demand for astronomers in Western Australia, and built a community that looks set to endure.}

\section{BY JAMES MITCHELL CROW}

$\mathrm{V}$ ery little happens in the outback of Western Australia - and that's how a growing group of astronomers likes it. The area is remote from urban centres and industry, so it is extremely radio-quiet: free of the 'noise' generated by cars, mobile phones and other trappings of civilization. That makes it an ideal spot in which to study radio waves from distant corners of the Universe, and is key to the nation's bid to host a prestigious international telescope, the Square Kilometre Array (SKA).

Five years ago, there was not a single astronomy researcher based in the state. Now, with the SKA on the horizon, two advanced pilot radio telescopes planned, high-level government funding available and a fledgling astronomy community looking to add to its ranks, Western Australia has the potential to be a research hub for years to come. But to succeed, it will have to sustain funding and attract enough researchers to this remote corner of the world.

\section{SKA BAND}

The astronomy expansion was sparked in 2006, when an international committee announced that Australia was one of two nations bidding to host the SKA, picked from a shortlist of four. The €1.5-billion (US\$2.1-billion) SKA will be the world's most powerful radio telescope, a continent-spanning array of dishes with a total collecting area of one square kilometre that will combine to make an instrument 50 times more sensitive than today's best. It is expected to help unlock some of the Universe's biggest mysteries, including the nature of dark energy and dark matter. Next year, the SKA selection panel will make its final decision on whether the telescope will be built on sites spanning Australia and New Zealand, or in South Africa.

Not every astronomer is convinced of the SKA's merits. Some wonder whether scientists and engineers can overcome technological, computing and energy-consumption challenges to maximize the array's effectiveness. "Any project of the scale that we are talking about has people who question whether this is the right way to spend the money," says Anton Zensus, director of the Max Planck Institute for Radio Astronomy in Bonn, Germany. 
